\title{
Channel Response Prediction for Abandoned Channel Restoration and Applicability Analysis
}

\author{
IL Hong, Joongu Kang*, Hongkoo Yeo, Yonguk Ryu \\ Department of Water Resources Research, Korea Institute of Construction Technology, Ilsan, Korea \\ E-mail: hongil93@kict.re.kr,jgkang02@kict.re.kr,yeo917@kict.re.kr,yuryu@kict.re.kr \\ Received February 9, 2011; revised March 22, 2011; accepted March 31, 2011
}

\begin{abstract}
As channel evaluation for abandoned channel restoration design, this study sought to exam channel changes from the past to the present and predict subsequently occurring river responses. For the methodology, channel geomorphology changes were evaluated through image analyses of annual aerial photographs to complement the limited river data. Channel responses were predicted using an analytical stable channel model, the SAM (Stable Channel Analytical Model) program, based on a stability theory as well as empirical equations for equilibrium channel. The results of the geomorphological channel changes showed that channels became narrower and bed levels became lower, whereas vegetated bars expanded. The channel response prediction results, narrower channels with deeper depths and mild slopes, were expected compared with the current condition. The channel response, obtained by the field measurement data, image information, and stability theory, are in relatively good agreements showing the reliability of the application suggested in this study. Consequently, the comprehensive channel evaluation approach is expected to be applicable to abandoned channel restoration designs from the aspects of channel geomorphology and hydraulics.
\end{abstract}

Keywords: Abandoned Channel Restoration, Channel Evaluation, Aerial Photograph, Image Analysis Method, Stable Channel Analytical Model, Regime Theory

\section{Introduction}

In the 1980s and 1990s, artificial river maintenance through channel straightening has resulted in many abandoned channels due to limiting natural rivers' meandering. Such a geomorphological change has given rise to many problems on river flows, drifting sands and life forms. Abandoned channel restoration seeks to ensure stable flows and maintain ecological diversity by securing flood plains that disappeared through channel straightening. With the recent emphasis on the value of river environments and the importance of flood plains including abandoned channels, measures for restoring the abandoned channels by integrating them into the river basin are sought. Since a river changes incessantly, however, the shape and physical features of a river are likely to vary depending on new environmental conditions when artificial disturbance occurs. Thus, for abandoned channel restoration, various reviews with regard to the hydrologic and hydraulic process, river shape process, chemical and biological features, and habitat evaluation are required. Especially for the channel design of river restoration, channel evaluation and channel response prediction as to whether the current channel stays stable or continuously changes are of importance due to the river dynamics. Channel evaluation is very important in selecting basic design factors such as channel shape, size, slope, and discharge distribution. Although geomorphologic, hydraulic, and hydrologic information of past and current rivers is required for channel evaluation, obtaining long-term past data of Korea's rivers is very difficult. Even though necessary data could exist, when river sites for actual evaluation were segmented, collecting the data would be almost impossible. However, Korea's aerial phonograph data have been accumulated since the latter half part of the 1960s when the river maintenance projects and farmland arrangement projects did not start yet. Therefore, the aerial photograph data can be very useful for the evaluation of historical channel changes. Moreover, the GIS analysis technology enables the use of image data to be relatively accurate and effective.

As a study applying an image analysis method, Katherine and Alan [1] evaluated channel shape changes for many years including sandbar change and sinuosity 
through analyses of longitudinal and cross sections. Sandra [2] analyzed the relationship of channel shape changes with flood frequency, flood size, rainfall, and discharge data. Veerle et al. [3] analyzed the short-term influence of artificial change on river changes based on bed materials and land use. Duncan et al. presented a direction for river management by assessing discharge balance according to channel shape changes [4]. Although there are many cases of applying image information to the river analyses, the image method has been rarely used for the purpose of channel design.

Methods of designing stable channels and equilibrium channel features have been proposed by many researchers based on analytical or empirical equilibrium channel theories. Copeland's method is used most commonly for stable channel evaluation and design in alluvial rivers and is one of the analytical methods selected for the SAM (Stable Channel Analytical Model) program developed by the US Army Corps of Engineers [5,6]. For an empirical approach, various equilibrium theory methods based on the downstream hydraulic geometry have been introduced. Julien and Wargadalam [7], Simmons and Albertson [8], Lacey (Wargadalam, re-cited) [9], and Klaassen and Vermeer [10] suggested empirical downstream hydraulic geometry equations. The river hydraulic geometry can not only examine the geometric characteristics of natural rivers but also be used for a model of stable channel or artificial channel designs from the river hydraulic aspect. Nowadays, it is also employed for a channel design of river restoration projects.

This study carried out channel evaluation on the restoration site of Cheongmi Stream's abandoned channel and examined the applicability of the channel evaluation method. The applicability of the method was assessed by comparing channel evaluation through an image analysis method and an existing equilibrium method with the measured data. For the channel evaluation through the image analysis method, channel planform changes were analyzed from 1969 to 2006 on the restoration site of the abandoned channel using the GIS analysis technique. For the channel evaluation through the equilibrium theory equations, equilibrium channel width and slope were estimated using the analytical methods and the previously suggested empirical equations.

\section{Study Area}

Cheongmi Stream, the target river of this study, is the primary tributary of South Han River; it has a length of $60.5 \mathrm{~km}$ and a basin area of $615.4 \mathrm{~km}^{2}$. Cheongmi Stream is a typical alluvial stream and the artificial river maintenance reaching a river's repair rate of more than $97 \%$ has been carried out. In the process of channel straightening of Cheongmi Stream, 20 abandoned channels were generated and mostly used as farmlands at present. Among the abandoned channels, the planned channel for the abandoned channel restoration, presented in Figure 1, is from Section $15+800$ to Section $16+$ 800 and the restoration area is $154,000 \mathrm{~m}^{2}$. The site including the restoration channel targeted for this study measures about $4 \mathrm{~km}$ as shown in Figure 1.

In Korea, the development of river basins and the dense land occupation cause limitations on channel restoration. In particular, the abandoned channel restoration of Cheongmi Stream with the 1-way type has considerable difficulty in being conducted since the current

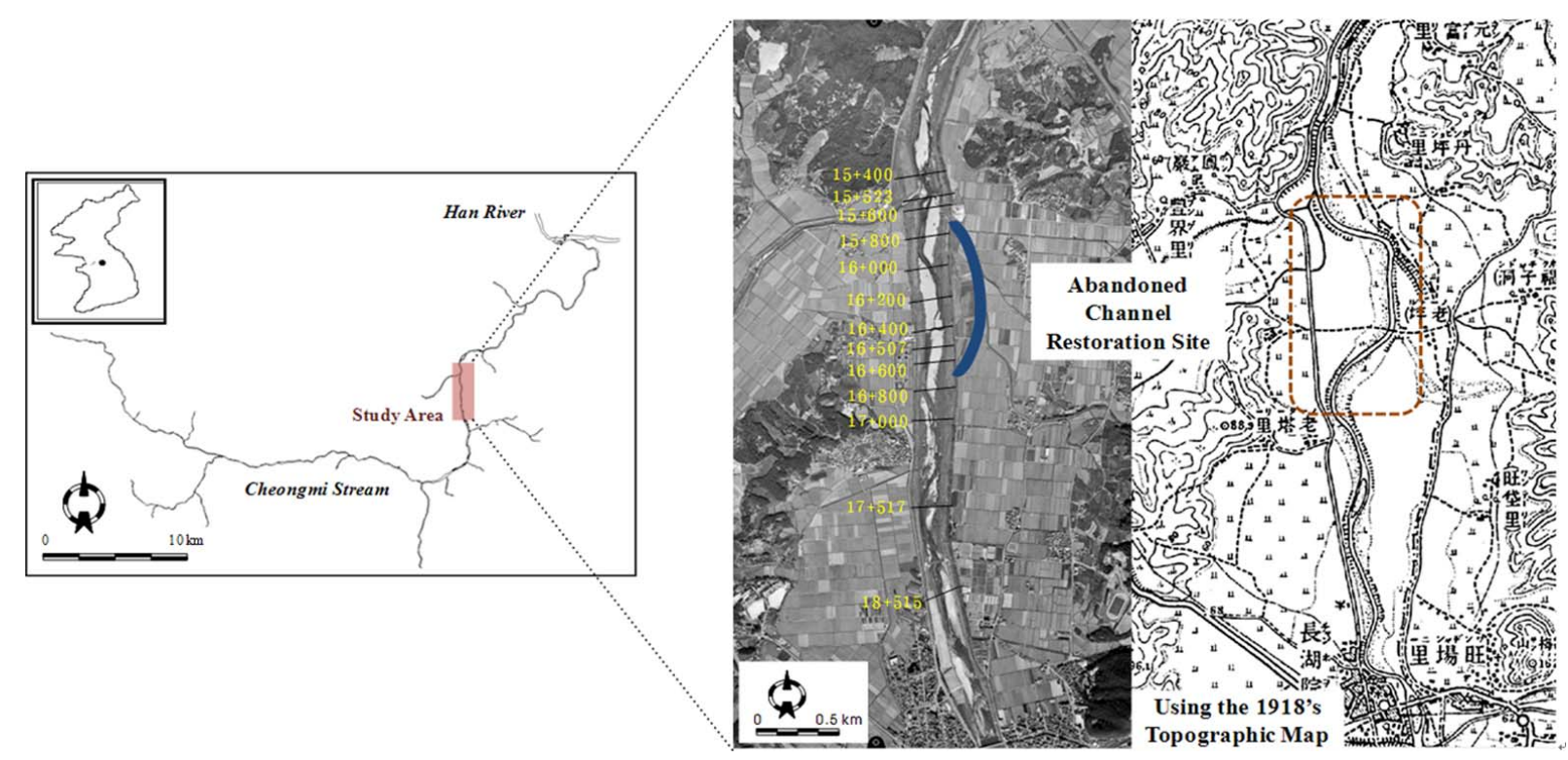

Figure 1. Study area and abandoned channel restoration site. 
straightened channel is in stable state. Note that the 1-way type is the method which restores the current channel into a naturally meandering condition. Hence, the abandoned channel restoration project of Cheongmi Stream has adopted the 2-way type that restores the abandoned channel while maintaining the current channel. Thus, the channel design focuses on predicting the hydraulic changes that may occur in the process that the current one channel becomes two channels and applying to the restoration.

\section{Channel Evaluation Using an Image Analysis Method}

For the spatial analysis of the channel using images, aerial photographs of 1969, 1974, 1981, 1992, 2000 and 2006 along with the 1918 geomorphology map were used. Matching the image data to the coordinate system in the GIS-based digital environment makes it possible to use all the image information of the area of interest. In particular, the aerial photographs used in this study were taken in April in the respective year, which possibly implies relatively similar climate conditions.

This study examines the area where the river maintenance mainly consisting of embankments and weir installations was carried out in 1983 and 1994. In general, geomorphology in the alluvial channel continuously changes by flood events and channel features such as a channel slope and a material kind and consequently the channel finally reaches equilibrium. However, planar fixations due to river maintenances such as channel straightening, channel width expansion and river structures cause the equilibrium channel to change. Figure 2 shows the channel changes on the restoration site through the yearly aerial photographs. In the figure, the weirs, a river structure, were found to be installed at 2 upstream places of the restoration site from the 2000 aerial photograph. The 1992 aerial photograph also shows the embankment installation in 1983. The river maintenances carried out in the respective year are likely to result in the rapid bar changes as well as flow changes shown in the figure.

Figure 3 presents the yearly channel change trends obtained from image analyses of the aerial photographs in Figure 2 in terms of sand bar, vegetated bar, vegetated area, farmland, water area, and parking zone. The channel state of 1969, which was relatively close to the natural river, shows a large difference from that of 2006 which was being stabilized after the completion of the river maintenances. In case of the restoration sections of the abandoned channel, alternate bars are located on both sides and the growing vegetation is observed in some areas.

To identify such changes quantitatively, the respective area and ratio of micro-landform state were calculated in the channels from the digitized images (Table 1). From the calculations of the channel characteristics, it is shown that there was no significant change in the total channel area between 1969 and 2006 while the vegetated bars, sand bars, and water area vary. The vegetated bars increased by about $33.4 \%\left(426,404 \mathrm{~m}^{2}\right)$, whereas $12.8 \%$ $\left(160,350 \mathrm{~m}^{2}\right)$ of the sand bars and $25.6 \%\left(322,145 \mathrm{~m}^{2}\right)$ of the water area decreased. In particular, the planform change in water area may indicate that the channel was a low-water channel including the thalweg along which the flow lasts.

Table 2 presents the yearly width change of the low-water channels, obtained by image-analyzing the aerial photographs in Figure 2, at some main cross sections including the restoration sites of the abandoned channels. The low-water channel width of each cross sec-

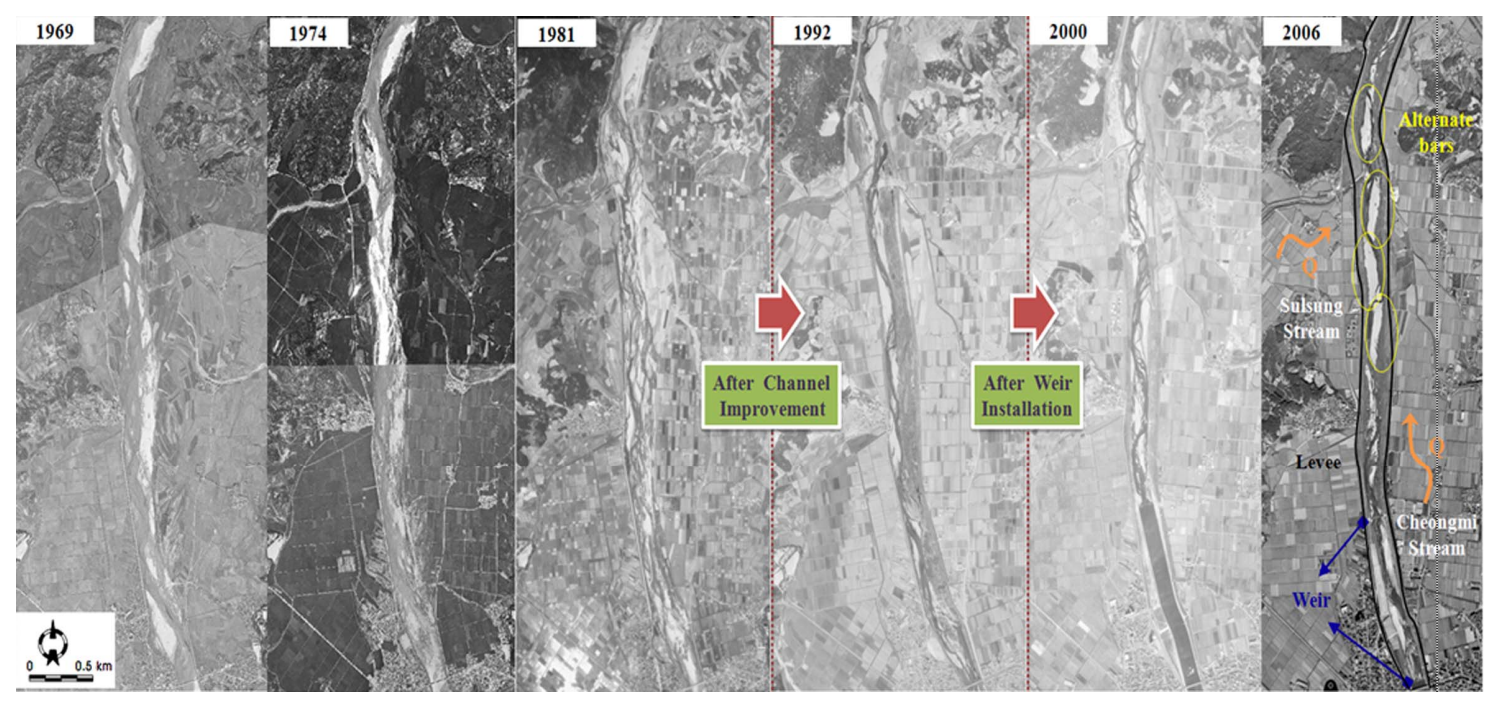

Figure 2. Aerial photographs of the study area from 1969, 1974, 1981, 1992, 2000, and 2006. 


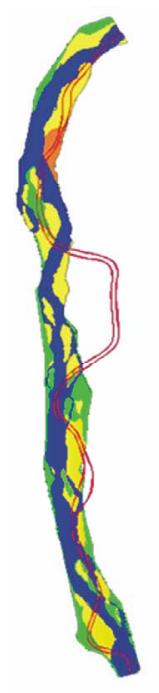

1969

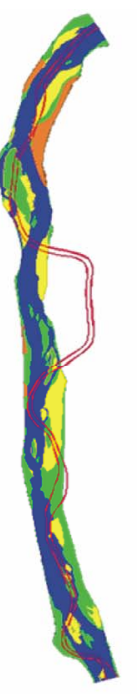

1974

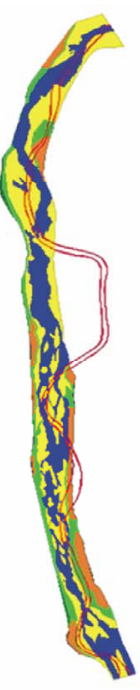

1981

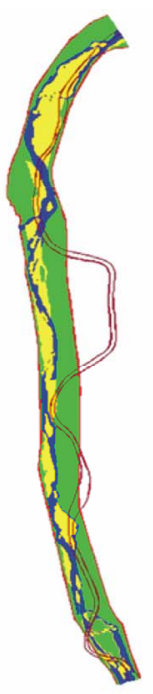

1992

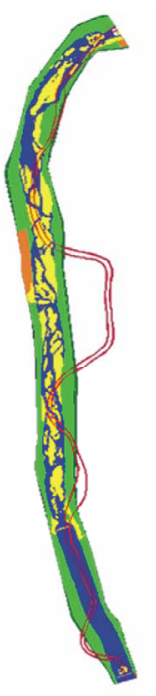

2000
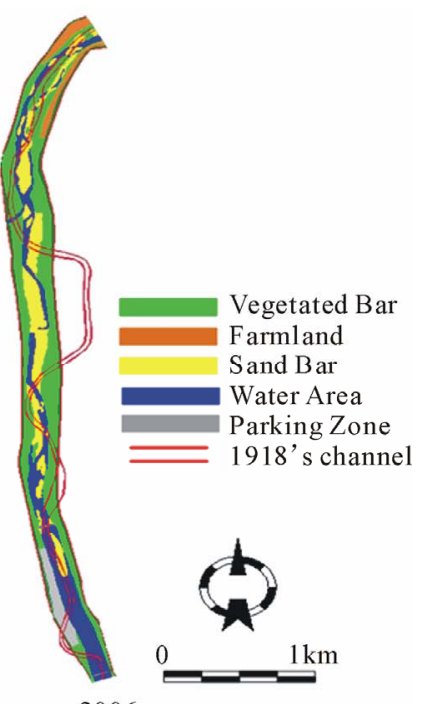

Figure 3. Example of a figure caption.

Table 1. Summary of 1969 and 2006 Micro-Landform characteristics in the study channel.

\begin{tabular}{|c|c|c|c|c|c|c|}
\hline Classification & Vegetated Bar $\left(\mathrm{m}^{2}\right)$ & Farmland $\left(\mathrm{m}^{2}\right)$ & Sand Bar $\left(\mathrm{m}^{2}\right)$ & Water Area $\left(\mathrm{m}^{2}\right)$ & Parking Zone $\left(\mathrm{m}^{2}\right)$ & Total Channel Area $\left(\mathrm{m}^{2}\right)$ \\
\hline 1969 & $\begin{array}{l}251,321 \\
(19.9 \%)\end{array}$ & $\begin{array}{l}36,588 \\
(2.9 \%)\end{array}$ & $\begin{array}{l}361,329 \\
(28.5 \%)\end{array}$ & $\begin{array}{l}616,854 \\
(48.7 \%)\end{array}$ & - & $\begin{array}{c}1,266,093 \\
(100 \%)\end{array}$ \\
\hline 1974 & $\begin{array}{l}353,568 \\
(28.2 \%)\end{array}$ & $\begin{array}{l}63,019 \\
(5.1 \%)\end{array}$ & $\begin{array}{l}222,133 \\
(17.7 \%)\end{array}$ & $\begin{array}{l}614,459 \\
(49.0 \%)\end{array}$ & - & $\begin{array}{c}1,253,179 \\
(100 \%)\end{array}$ \\
\hline 1981 & $\begin{array}{l}143,280 \\
(11.4 \%)\end{array}$ & $\begin{array}{l}130,391 \\
(10.3 \%)\end{array}$ & $\begin{array}{l}470,901 \\
(37.4 \%)\end{array}$ & $\begin{array}{l}515,119 \\
(40.9 \%)\end{array}$ & - & $\begin{array}{c}1,259,691 \\
(100 \%)\end{array}$ \\
\hline 1992 & $\begin{array}{l}752,569 \\
(58.4 \%)\end{array}$ & - & $\begin{array}{l}298,071 \\
(23.2 \%)\end{array}$ & $\begin{array}{l}237,195 \\
(18.4 \%)\end{array}$ & - & $\begin{array}{c}1,287,836 \\
(100 \%)\end{array}$ \\
\hline 2000 & $\begin{array}{l}618,707 \\
(47.3 \%)\end{array}$ & $\begin{array}{l}26,210 \\
(2.0 \%)\end{array}$ & $\begin{array}{l}255,834 \\
(19.5 \%)\end{array}$ & $\begin{array}{l}408,285 \\
(31.2 \%)\end{array}$ & - & $\begin{array}{c}1,309,036 \\
(100 \%)\end{array}$ \\
\hline 2006 & $\begin{array}{l}677,725 \\
(53.3 \%)\end{array}$ & $\begin{array}{l}50,632 \\
(4.0 \%)\end{array}$ & $\begin{array}{l}200,979 \\
(15.8 \%)\end{array}$ & $\begin{array}{l}294,709 \\
(23.1 \%)\end{array}$ & $\begin{array}{l}47795 \\
(3.8 \%)\end{array}$ & $\begin{array}{c}1,271,840 \\
(100 \%)\end{array}$ \\
\hline
\end{tabular}

tion appears to decrease gradually compared to the past.

The characteristics of channel planform changes presented in Figure 3. Table 1 and Table 2 show the channel became gradually narrower and the total bars increased. As for the bar changes in detail, the sand bars decreased while the vegetated bars increased. The tendency of bar change shows the process of vegetation gradually taking root with the fixation of the sand bars. Consequently, the artificial river maintenances show that natural change gradually decreases and only thalweg of the low-water channel changes.

\section{Prediction of Stable Channel Using Equilibrium Methods}

For the channel response prediction, this study employed the previously suggested methods based on both analytical and empirical equilibrium bed theories. This study evaluated the current channel's stability by using Copeland's method [5], one of the mostly used analytical methods, as a basic module for the planned site of Cheongmi Stream's abandoned channel restoration. Copeland's method, one of the analytical methods used for SAM of the US Army Corps of Engineers, is most widely used for evaluation and design of stable channels in alluvial rivers [6]. This method is similar to that of Abou-Seida and Saleh [11]. Among 3 unknown variables (channel width, slope, and depth of a stable channel), any two ones are calculated first. For the third unknown one, the most suitable solution for design conditions and geomorphological conditions is selected from several solutions by a designer. 
For the empirical method, the equations of Julien and Wargadalam [7], Simmons and Albertson [8], Lacey (Wargadalam, re-cited) [9], and Klaassen and Vermeer [10] were used and compared. The equations of Julien and Wargadalam, Simmons and Albertson, Lacey, and Klaassen and Vermeer are typical empirical equilibrium bed equations related to downstream hydraulic geometry.

\subsection{Stable Channel Prediction Using Analytical Methods}

The stable channel slope in the restoration site of Cheongmi Stream was calculated using SAM to which Copeland's method is applied. The input data for the stable channel design used for SAM include the following: bankfull discharge, $Q_{b}=488 \mathrm{~m}^{3} / \mathrm{s}$; specific gravity, $G=2.65$; valley slope, $S_{v}=-0.00088$; bank side slope, 2.3; bank roughness, 0.03 ; bed material gradation, $d_{84}=$ $2.18 \mathrm{~mm}, d_{50}=1.1 \mathrm{~mm}, d_{16}=0.63 \mathrm{~mm}$.

For the restoration site of Cheongmi Stream, the calculated bottom widths using SAM and the corresponding converted top widths are presented in Table 3 . The calculation for Cheongmi Stream gives 21 solutions of the stable channel bottom widths ranging from $7.92 \mathrm{~m}$ to $160.02 \mathrm{~m}$, the water depths for the bankfull discharge ranging from $2.09 \mathrm{~m}$ to $7.61 \mathrm{~m}$, and the energy slopes ranging from 0.000912 to 0.000762 . The relationships of the slope with the width and the depth are presented in Figure 4. The conditions for the widths, depths and slopes plotted in Figure $\mathbf{4}$ mean a theoretically stable state. The figure indicates that a river with a condition falling under the region outside the relation curves could get unstable. The unstable state is expected to be caused by either erosion for the conditions over the relation curves or sedimentation for the conditions under the relation curve. Figure 4 shows the calculated 21 solutions for the stable channel including 1 solution with minimum stream power.

Table 4 presents the surface curve data of Cheongmi Stream in the current condition calculated using HEC-RAS based on the geomorphological data measured in 2008. Note that the region from Section $15+8$ to

Table 2. Changes in the low flow channel width along Cheongmi Stream.

\begin{tabular}{ccccc}
\hline \multirow{2}{*}{ Year } & \multicolumn{5}{c}{ Cross section number } \\
& $15+523$ & $16+400$ & $16+507$ & $17+517$ \\
\hline 1969 & 99.8 & 108.6 & 132.8 & 87.5 \\
1992 & 46.4 & 28.8 & 31.3 & 35.0 \\
2000 & 39.4 & 18.0 & 53.2 & 66.3 \\
2006 & 36.3 & 13.2 & 42.3 & 58.2 \\
\hline
\end{tabular}

Table 3. Stable channel dimensions calculated using the SAM program.

\begin{tabular}{cccccccc}
\hline $\begin{array}{c}\text { Bottom } \\
\begin{array}{c}\text { Width } \\
(\mathrm{m})\end{array}\end{array}$ & $\begin{array}{c}\text { Depth } \\
(\mathrm{m})\end{array}$ & $\begin{array}{c}\text { Top } \\
\text { Width } \\
(\mathrm{m})\end{array}$ & $\begin{array}{c}\text { Energy } \\
\text { Slope }\end{array}$ & $\begin{array}{c}\text { Hyd } \\
\text { Raidus } \\
(\mathrm{m})\end{array}$ & $\begin{array}{c}\text { Velocity } \\
(\mathrm{m} / \mathrm{s})\end{array}$ & $\begin{array}{c}\text { Froude } \\
\text { Number }\end{array}$ & $\begin{array}{c}\text { Bed } \\
\text { Regime }\end{array}$ \\
\hline 7.92 & 7.61 & $\mathbf{4 2 . 9 3}$ & 0.000912 & 4.21 & 2.53 & 0.29 & Lower \\
16.15 & 6.90 & $\mathbf{4 7 . 8 9}$ & 0.000688 & 4.35 & 2.21 & 0.27 & Lower \\
24.08 & 6.20 & $\mathbf{5 2 . 6 0}$ & 0.000617 & 4.30 & 2.05 & 0.26 & Lower \\
32.00 & 5.58 & $\mathbf{5 7 . 6 7}$ & 0.000589 & 4.16 & 1.95 & 0.26 & Lower \\
39.93 & 5.05 & $\mathbf{6 3 . 1 6}$ & 0.000579 & 3.98 & 1.87 & 0.27 & Lower \\
$\mathbf{4 3 . 7 0}$ & $\mathbf{4 . 8 3}$ & $\mathbf{6 5 . 9 2}$ & $\mathbf{0 . 0 0 0 5 8 0}$ & $\mathbf{3 . 9 0}$ & $\mathbf{1 . 8 4}$ & $\mathbf{0 . 2 7}$ & Lower \\
48.16 & 4.59 & $\mathbf{6 9 . 2 7}$ & 0.000580 & 3.77 & 1.81 & 0.27 & Lower \\
56.08 & 4.22 & $\mathbf{7 5 . 4 9}$ & 0.000587 & 3.59 & 1.76 & 0.27 & Lower \\
64.01 & 3.90 & $\mathbf{8 1 . 9 5}$ & 0.000598 & 3.40 & 1.71 & 0.28 & Lower \\
71.93 & 3.63 & $\mathbf{8 8 . 6 3}$ & 0.000609 & 3.23 & 1.67 & 0.28 & Lower \\
80.16 & 3.39 & $\mathbf{9 5 . 7 5}$ & 0.000623 & 3.06 & 1.64 & 0.28 & Lower \\
88.09 & 3.18 & $\mathbf{1 0 2 . 7 2}$ & 0.000637 & 2.91 & 1.61 & 0.29 & Lower \\
96.01 & 3.00 & $\mathbf{1 0 9 . 8 1}$ & 0.000651 & 2.78 & 1.58 & 0.29 & Lower \\
103.94 & 2.85 & $\mathbf{1 1 7 . 0 5}$ & 0.000665 & 2.66 & 1.55 & 0.29 & Lower \\
112.17 & 2.70 & $\mathbf{1 2 4 . 5 9}$ & 0.000680 & 2.54 & 1.53 & 0.30 & Lower \\
120.09 & 2.57 & $\mathbf{1 3 1 . 9 1}$ & 0.000694 & 2.43 & 1.5 & 0.30 & Lower \\
128.02 & 2.46 & $\mathbf{1 3 9 . 3 4}$ & 0.000709 & 2.34 & 1.48 & 0.30 & Lower \\
135.94 & 2.36 & $\mathbf{1 4 6 . 8 0}$ & 0.000723 & 2.25 & 1.46 & 0.30 & Lower \\
144.17 & 2.26 & $\mathbf{1 5 4 . 5 7}$ & 0.000737 & 2.17 & 1.45 & 0.31 & Lower \\
152.10 & 2.17 & $\mathbf{1 6 2 . 0 8}$ & 0.000751 & 2.09 & 1.43 & 0.31 & Lower \\
160.02 & 2.09 & $\mathbf{1 6 9 . 6 3}$ & 0.000762 & 2.02 & 1.41 & 0.31 & Lower \\
\hline & & & & & & & \\
\hline
\end{tabular}

Section $16+8$ is the planned area for the abandoned channel restoration. The channel top widths by HEC-RAS is calculated from $158 \mathrm{~m}$ to $236 \mathrm{~m}$ when a bankfull discharge occurs, which are overestimated compared with the stable channel top widths obtained by the Copeland method. Moreover, in case the abandoned channel restoration is carried out, the channel top widths are expected to have a larger value rather than the stable channel width since newly restored channel widths will be added to the existing channel widths for the total width estimation. Although the depths of the stable channel obtained by SAM range from $2.09 \mathrm{~m}$ to $7.61 \mathrm{~m}$, the depths of the channel in current state by HEC-RAS are estimated from $1.52 \mathrm{~m}$ to $2.09 \mathrm{~m}$. The current channel slopes are slightly larger than those of the stable channel and the differences are negligible. From the comparisons, the stable channel estimated by SAM is expected to have narrower width, deeper depth and milder slope compared with the current channel condition and the HEC-RAS estimation. In particular, the result that the current channel width is wider than that of the stable channel favorably accounts for why bars develop in the current channel. 


\subsection{Channel Evaluation Using Empirical Equilibrium Bed Equations}

This study predicted the stable channel width, i.e. equilibrium channel width, of the abandoned channel restoration site of Cheongmi Stream using the equilibrium equations, which are suggested by Julien and Wargadalam, Simmons and Albertson, Lacey and Klaassen and Vermeer.

Julien and Wargadalam used the concepts of resistance, sediment transport, continuity, and secondary flow to develop analytical hydraulic geometry equations as follows:

$$
\begin{gathered}
h=0.2 Q^{2 /(5+6 m)} d_{s}^{6 m /(5+6 m)} S^{-1 /(5+6 m)} \\
W=1.33 Q^{(2+4 m) /(5+6 m)} d_{s}^{-4 m /(5+6 m)} S^{-(1+2 m) /(5+6 m)} \\
V=3.76 Q^{(1+2 m) /(5+6 m)} d_{s}^{-2 m /(5+6 m)} S^{(2+2 m) /(5+6 m)} \\
\tau_{*}=0.121 Q^{2 /(5+6 m)} d_{s}^{-5 /(5+6 m)} S^{(4+6 m) /(5+6 m)}
\end{gathered}
$$

$$
m=1 / \ln \left(\frac{12.2 h}{d_{s}}\right)
$$

where $h(\mathrm{~m})$ is the average flow depth, $W(\mathrm{~m})$ is the average width, $V(\mathrm{~m} / \mathrm{s})$ is the average one-dimensional velocity, $Q$ (cfs) is the discharge, $S$ is the channel slope, $\tau^{*}$ is the Shields parameter, $d_{s}(\mathrm{~m})$ is the sediment size, and $m$ is the parameter determined from roughly estimated flow depth.

Simons and Albertson [8] used five sets of data from canals in India and America to develop equations and used the relationship graph of a wetted perimeter with a discharge and a channel width to determine equilibrium channel width.

$$
P=2.51 Q^{0.512}
$$

\begin{tabular}{|c|c|c|c|c|c|c|}
\hline $\mathrm{Q}\left(\mathrm{m}^{3} / \mathrm{s}\right)$ & River station & Depth (m) & Energy Slope & Velocity (m/s) & Top Width (m) & Froude Number \\
\hline \multirow{7}{*}{488} & $16+800$ & 1.52 & 0.000980 & 1.38 & 232.98 & 0.36 \\
\hline & $16+600$ & 1.65 & 0.001258 & 1.64 & 179.59 & 0.41 \\
\hline & $16+507$ & 2.09 & 0.000669 & 1.40 & 166.97 & 0.31 \\
\hline & $16+400$ & 2.08 & 0.000747 & 1.48 & 158.60 & 0.33 \\
\hline & $16+200$ & 1.79 & 0.000898 & 1.46 & 186.31 & 0.35 \\
\hline & $16+000$ & 1.81 & 0.000850 & 1.43 & 188.78 & 0.34 \\
\hline & $15+800$ & 1.57 & 0.000873 & 1.32 & 236.08 & 0.34 \\
\hline
\end{tabular}

where $P(\mathrm{ft})$ is the wetted perimeter.

Lacey (from Wargadalam) [9] developed a power relationship for determining wetted perimeter based on discharge.

Table 4. Hydraulic characteristics of the bankfull discharge condition for Cheongmi Stream.

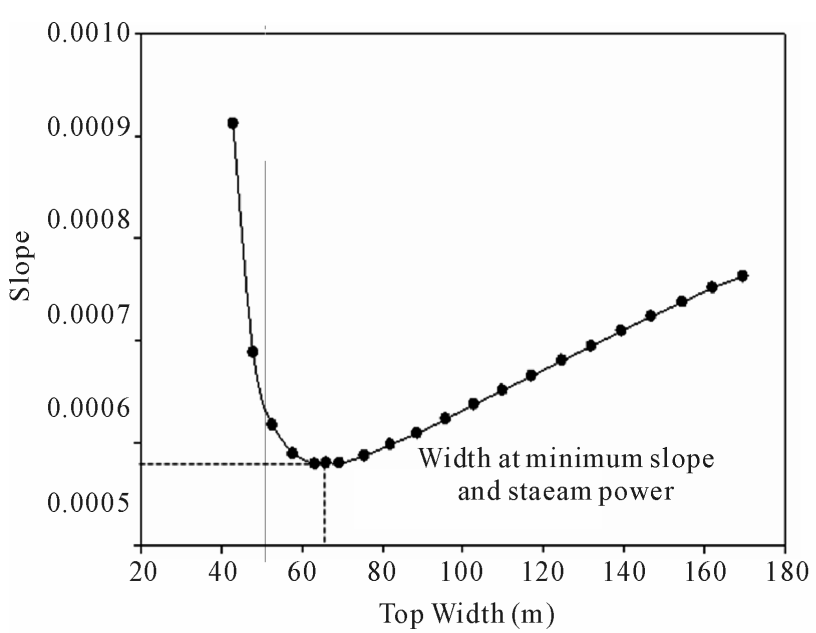

(a) Top width

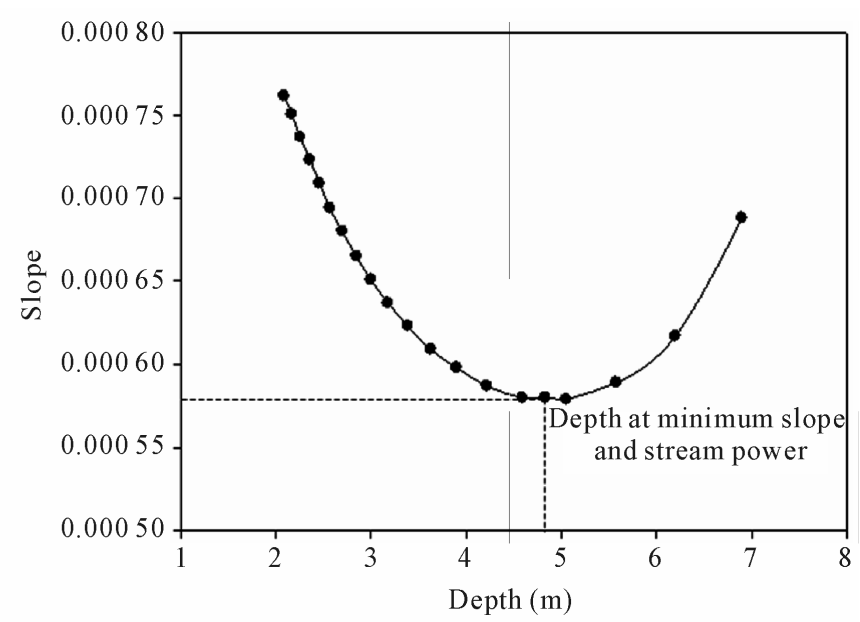

(b) Depth

Figure 4. Stable channel slope, depth and slope from SAM. 


$$
P=2.667 Q^{0.5}
$$

For wide and shallow channels, the wetted perimeter is approximately equal to the width.

Klaassen and Vermeer [10] used data from Jamuna River in Bangladesh to develop a width-discharge relationship for braided rivers.

$$
W=16.1 Q^{0.53}
$$

The input data for the calculation of equilibrium channel width using the empirical equilibrium equations are: the bankfull discharge, $Q_{b}=488 \mathrm{~m}^{3} / \mathrm{s}$; the slope between Section $15+8$ and Section $16+8, S=0.00073$; the hydraulic depth of Section $16+4,2.08 \mathrm{~m}$; the bed material size, $d_{50}=1.1 \mathrm{~mm}$.

The equilibrium channel widths of the restoration site of Cheongmi Stream obtained using the downstream hydraulic geometric equations and equilibrium bed equations are compared with the current width for the bankfull discharge estimated by HEC-RAS in Figure 5. Three equations except the equation of Klaassen and Vermeer [10] predict the equilibrium channel width to be between $100 \mathrm{~m}$ and $145 \mathrm{~m}$, which are smaller than the HEC-RAS channel width, $158.6 \mathrm{~m}$. Note that the equation of Klaassen and Vermeer over-predicting the channel width as $428.2 \mathrm{~m}$ has regional limitations considering a specific region and considers only a braided channel. Although Section $16+4$ is the narrowest cross section within the restoration site, the channel width by HEC-RAS is larger than the stable channel width predicted by the three equilibrium equations.

\section{Comparison and Discussion}

The stable channel predictions for the abandoned restoration site of Cheongmi Stream carried out by both the analytical and the empirical approaches of the equilib-

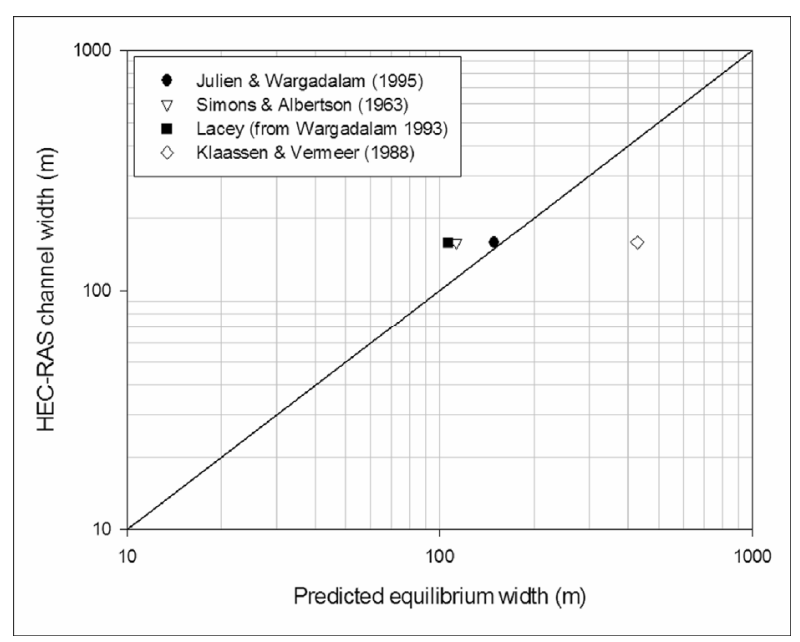

Figure 5. Equilibrium width using downstream hydraulic geometry equations in Cheongmi Stream. rium method are compared with the channel conditions by HEC-RAS in Table 5. Among the methods for the empirical estimation, Klaassen and Vermeer [10] is excluded because of its limitations in application and overestimation of the top width. Both the channel slope with the minimum stream power estimated from SAM and the equilibrium slope from Julien and Wargadalam [7] are larger than the current slope, which means the current slope is in stable state. Since the change of Cheongmi Stream into a natural meandering channel for a milder slope is limited due to its current stable condition of slope, it is expected that a weir and a drop structure would supplement the adjustment of slope for abandoned channel restoration designs. Moreover, Cheongmi Stream's current conditions calculated from HEC-RAS, the wider width and shallower depth compared to the predictions from both SAM and empirical equilibrium equations, imply that a narrower channel can be more effective in terms of hydraulics and geomorphologically more stable.

The applicability of the comprehensive and complementary assessment using the analytical and empirical equilibrium estimations of a stable channel to an abandoned channel restoration design was examined through comparisons with the survey data measured in 1983, 1994, and 2004 and the image analysis of the aerial photographs. From the thalweg profiles shown in Figure 6, the bed slope change from 1983 to 2004 was not significant; the bed level was lowered gradually, however. The average deepest bed level (El.) was $55.6 \mathrm{~m}$ in 1983, 54.6 $\mathrm{m}$ in 1994, and $54.0 \mathrm{~m}$ in 2004. Cross section shapes of Sections $15+523,16+507,17+517$, and $18+515$ from 1983 to 2004 are compared in Figure 7. The average channel width of the four cross sections gets narrow by about $30 \mathrm{~m}$ from $309.7 \mathrm{~m}$ in 1983 to $279.8 \mathrm{~m}$ in 2004 . From the comparisons of the bed level and the channel width, the channel tends to keep the mild slope and get deeper and wider, which is likely to be a change pattern to a stable channel. In addition, the wider current channel

Table 5. Results of SAM, equilibrium methods, and HEC-RAS for Section $16+400$.

\begin{tabular}{ccccc}
\hline $\begin{array}{c}\text { Bankfull } \\
\text { Discharge } \\
\left(\mathrm{m}^{3} / \mathrm{s}\right)\end{array}$ & Methods & Slope & $\begin{array}{c}\text { Width } \\
(\mathrm{m})\end{array}$ & $\begin{array}{c}\text { Depth } \\
(\mathrm{m})\end{array}$ \\
\hline & $\begin{array}{c}\text { SAM } \\
\text { Julien and } \\
\text { Wargadalam }\end{array}$ & 0.000580 & 65.92 & 4.83 \\
& $\begin{array}{c}\text { Simons and } \\
\text { Albertson } \\
\text { Lacey (from }\end{array}$ & - & 112.9 & - \\
& $\begin{array}{c}\text { Wargadalam ) } \\
\text { HEC-RAS } \\
\text { (Present Condition) }\end{array}$ & 0.000700 & 143.9 & - \\
& & & 106.7 & - \\
\hline
\end{tabular}


width rather than the predicted stable channel width explains why the bars around the target channel have developed. The surveyed data as well as the information about the area of the bars and waters from the aerial image analysis show the pattern that the channel gets narrow and vegetation takes root on the subsequently developing bars. The historical channel change observed from the measured data including the survey and aerial photographs supports the channel response prediction by the equilibrium methods.

\section{Conclusions}

This study suggested an assessment method for channel response prediction using an aerial image analysis method and the analytical and empirical equilibrium equations

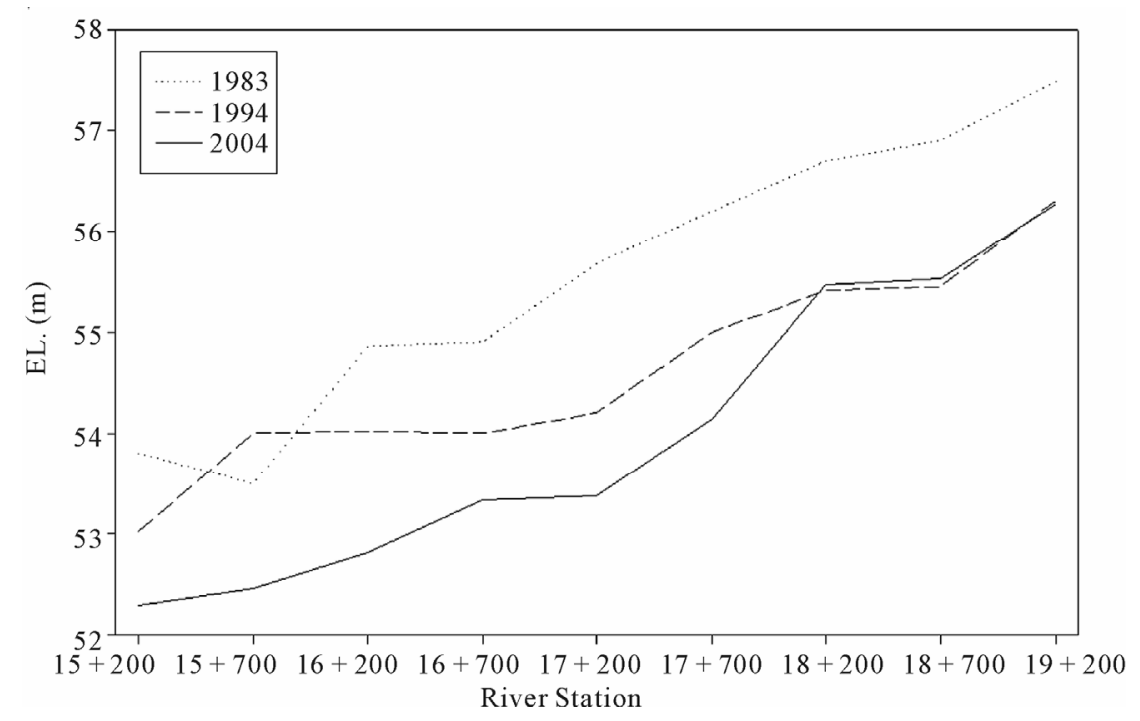

Figure 6. Historical thalweg profiles of the study reach.
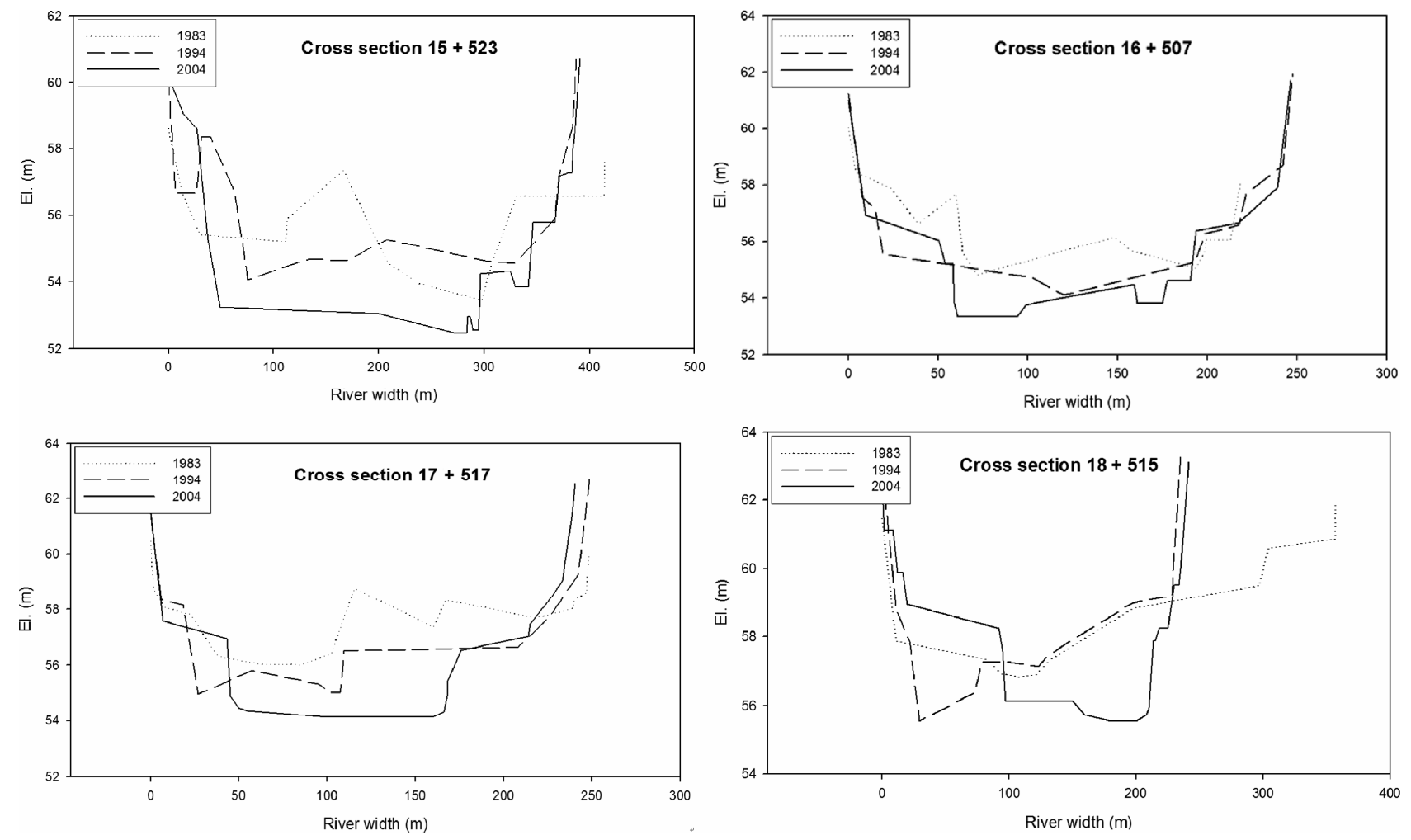

Figure 7. Cross section changes between 1983 and 2004 for the study reach. 
for a stable channel condition. This approach in this study can be a complementary way to estimate a channel condition and subsequently suggest a plan for channel designs or restoration projects since there has been a need of an alternative channel estimation method due to the lack of past measurement data in Korea. The current channel's state could be identified using the image analysis method that shows macro phenomena on changes in channel geomorphology such as channel width and bar area. Although the image analysis results have a limitation, i.e., providing only 2D information, the image analysis method can be a very important method in channel evaluation in a situation wherein sufficient data have not been accumulated. For a stable channel state, the analytical stable channel analysis and empirical equilibrium bed equations provided quantitative values to design the stable and equilibrium channel. Based on findings of change pattern and values of stable channel features, the method is expected to suggest a channel plan from the channel's geomorphological and hydraulic aspects.

In this study, the channel response estimation method was examined by applying it to the abandoned channel restoration site of Cheongmi Stream. From the comparisons in the channel features between the existing measured data such as the survey data and aerial images and the predictions of the study reach, the change pattern predicted by the suggested method was found to be relatively consistent with the measurements; thus confirming the reliability of the applicability. The channel of the restoration site is found to get narrower and deeper, which is a progress into a stable channel. Based on the findings from the comprehensive method, this study proposes designing the abandoned channel to be restored as a narrower one and supplying minimum discharge favorable to the ecosystem since the abandoned channel restoration in the target site plans to use a 2-way type. In addition, since the current channel slope is higher than the equilibrium channel slope, this study also suggested installing slope-adjusting structures such as a drop structure to reach the equilibrium bed.

\section{Acknowledgements}

This study was partially supported by the 2006 Core Construction Technology Development Project (06KSHS-
B01) through ECORIVER21 Research Center in KICTEP of MLTM KOREA.

\section{References}

[1] F. L. Katherine and W. Alan, "River Channel Planform Change: Software for Historical Analysis," Geomorphology, Vol. 29, No. 1-2, 1999, pp. 107-120. doi:10.1016/S0169-555X(99)00009-4

[2] J. W. Sandra, "Medium and Short-Term Channel Planform Changes on the River Tay and Tummel, Scotland," Geomorphology, Vol. 34, No. 3-4, 2000, pp. 195-208. doi:10.1016/S0169-555X(00)00007-6

[3] V. Veerle, M. Armando, G. Gerard, P. Jean, D. Gerd and D. Seppe, "River Channel Response to Short-Term Human-Induced Change in landscape Connectivity in Andean Ecosystems," Geomorphology, Vol. 72, No. 3-4, 2005, pp. 340-353.

[4] W. Duncan, W. Jeff and B. Louise, "Gravel Extraction and Planform Change in a Wandering Gravel-Bed River: The River Wear, Northern England," Geomorphology, Vol. 94, No. 1-2, 2008, pp. 131-152. doi:10.1016/j.geomorph.2007.05.003

[5] R. R. Copeland, “Application of Channel Stability Methods-Case Studies," US Army Corps of Engineers, Waterways Experiment Station, Vicksburg, Mississippi, 1994.

[6] S. H. Scott, "Application of the SAM Computer Program for Truckee River Stable Channel Analysis,” US Army Corps of Engineers, Coastal and Hydraulics Laboratory, 2006.

[7] P. Y. Julien and J. Wargadalam, "Alluvial Channel Geometry: Theory and Applications,” Journal of Hydraulic Engineering, Vol. 121, No. 4, 1995, pp. 312-325. doi:10.1061/(ASCE)0733-9429(1995)121:4(312)

[8] D. B. Simons and M. L. Albertson, "Uniform Water Conveyance Channels in Alluvial Materials," Journal of the Hydraulics Division, Vol. 68, No. 5, 1960, pp. 33-71.

[9] J. Wargadalam, "Hydraulic Geometry of Alluvial Channels,” Colorado State University, Fort Collins, CO., 1993.

[10] G. J. Klaassen and K. Vermeer, "Channel Characteristics of the Braiding Jamuna River, Bangladesh,” International Conference on River Regime, Willingford, 18-20 May 1988, pp. 173-189.

[11] M. M. Abou-Seida, and M. Saleh, "Design of Stable Alluvial Channels,” Journal of Hydraulic Research, Vol. 25, No. 4, 1987, pp. 433-446. doi:10.1080/00221688709499261 